\title{
Cognitive and social predictors of generalized anxiety disorder symptoms among fresh undergraduates in Uganda
}

\author{
GREGORY C. UMEH ${ }^{1 *}$ and PAUL BANGIRANA ${ }^{2}$
}

${ }^{1}$ Department of Mental Health \& Community Psychology, School of Psychology, Makerere University, Kampala, Uganda

${ }^{2}$ Department of Psychiatry, School of Medicine, Makerere University, Kampala, Uganda

\begin{abstract}
Background: Generalized anxiety disorder (GAD) is common. It accounts for about one out of four anxiety related clinic consultations. The prevalence of this common disorder and the associated factors in Ugandan students are unknown. The objectives of this study were to determine the prevalence of GAD symptoms, and to evaluate its association with intolerance of uncertainty and parental attachment among fresh undergraduates in Uganda.

Methods: The research utilized a cross-sectional approach. Non-clinical participants from 8 colleges (mean age $21.24 ; 59.7 \%$ males, $40.3 \%$ females) completed self-report inventories measuring intolerance of uncertainty, parental attachment and GAD symptoms. Pearson's correlations were run to test relationship between the independent and dependent variables, a stepwise regression analysis was used to identify predictors of GAD, while controlling for age.

Results: A total of 401 students were involved in the study. The prevalence of GAD symptoms was $28.9 \%$. There was a significant positive relationship between GAD symptoms and intolerance of uncertainty $(r=$ $0.30, p=0.001)$ and with parental attachment $(r=0.21, p=0.001)$. Intolerance of uncertainty and parental attachment, predicted GAD symptoms $(r=0.30,95 \% \mathrm{Cl}=0.30$ to $6.16, \mathrm{p}=0.001 ; \mathrm{r}=0.21,95 \% \mathrm{Cl}=0.21$ to 4.19, $\mathrm{p}=0.001$, respectively).

Conclusion: The present research suggests that GAD symptoms are prevalent among fresh undergraduates and are associated with both intolerances of uncertainty and parental attachment. Psychological interventions for undergraduate students may be needed to target these factors.
\end{abstract}

Keywords: anxiety disorder, prevalence, symptoms, students, university, Uganda

\section{Introduction}

Generalized anxiety disorder (GAD) is very common and about one out of four anxiety related clinic consultations is due to GAD, with $34 \%$ correctly diagnosed by primary care physicians (Wittchen et al., 2002). It is characterized by chronic worry (Comer \& Kendall, 2004) and is twice common in women than in men (Tyrer \& Baldwin, 2006). The prevalence rate in the general population is $3.1 \%$ in United States of America (Kessler et al., 2005), 1.9\% in Norway (MunkJorgensen et al., 2006), 4.1\% in Belgium (Ansseau et al., 2005) and 3\% in low income countries (Lee et al., 2009). Cognitive factors like intolerance of uncertainty (Behar et al., 2005; Sugiura, 2007; Tan et al., 2010) and social factors like parental attachment (Hale et al., 2006; Wood, 2006) are strong predictors of GAD. Some studies have indicated a strong positive correlation between $G A D$, intolerance of uncertainty, negative belief and parentification (Hale et al., 2006; Sugiura, 2007; Tan et al., 2010).

Intolerance of uncertainty leads to worrying (Holaway et al., 2006) and overtime uncontrolled worrying leads to anxiety (Behar et al., 2005). Individuals who are intolerant of uncertainty will worry over little things and may develop the tendency to see worrying as a way of solving their problems (Dugas et al., 2004). They are more likely to see situations as stressful, disturbing and unacceptable. Pathological worriers maintain their problem by worrying and more

\footnotetext{
* Correspondence E-mail: umehgreg@yahoo.com
} 
worrying only opens the gates to more worrying leaving the individual more at risk of all the consequences of GAD (Ruscio \& Borkovec, 2004).

Parental attachment has great influence on a child's growth and development into an independent and successful adult (Bowlby, 1977; Hale et al., 2006). Parental attachment has implications on how children behave and react to life's situations such as stress, relationship challenges, success, failure, loss of close family members, living away from home and so forth. Most often, a child who is insecurely attached to his/her parents grows up with limited social skills, and may find adjustment to change difficult and stressful (Hudson \& Rapee, 2002; Viana \& Rabian, 2008). An insecure child is less confident of his skills and abilities and may find it difficult negotiating and maintaining relationship with others, and the aftermath is tension, anxiety and frustration in the face of challenges and tasks requiring swift decision (Hudson \& Rapee, 2002; Wood, 2006; Jinyao et al., 2012). The child may eventually grow up into adulthood, more anxious and with limited coping skills (Hudson \& Rapee, 2002; Wood, 2006; Jinyao et al., 2012).

Fresh undergraduates go through stress adjusting to new environment and grappling with the challenges of freedom, work and independence. Previous researches on GAD have not specifically focused on the role of intolerance of uncertainty and parental attachment in the evolution of GAD among fresh undergraduates in developing countries including Uganda. Students that manifest GAD symptoms are less likely to adjust well to stress, which may result in personal, interpersonal and academic difficulties (Ozan et al., 2010). In Uganda, there is little research on the prevalence of GAD, and its relationship to intolerance of uncertainty and parental attachment. This study was therefore, carried out to assess the prevalence of GAD symptoms and evaluated the association between GAD symptoms, intolerance of uncertainty and parental attachment among fresh undergraduates in Uganda.

\section{Materials and Methods}

\section{Study site, design and participants}

The cross-sectional quantitative study was carried out among fresh undergraduates at Makerere University, Kampala, Uganda. The target population was students pursuing undergraduate degree programmes in the main campus, Kampala. The study population was fresh undergraduate students, from eight colleges. Participants for the study were sampled from the study population with characteristics that cut across sex, age and socio-cultural diversities.

\section{Sampling procedure and sample size}

Respondents were recruited through a stratified random sample technique that guaranteed equal chance of selection. Eight schools were selected at random from eight colleges of Makerere University, and eight departments also selected at random from these eight schools. Each college, school or department was selected once and no more than one school per college, to ensure even and near normal representation as possible. Sample size estimation was done using Yamane's formula (Israel, 2012). $\mathrm{n}=\mathrm{N} / 1+\mathrm{N}(\mathrm{e})^{2}$; where $\mathrm{n}=$ sample size; $\mathrm{N}=$ population size; $\mathrm{e}=$ desired level of precision ( $5 \%$ ) with an assumption of a $95 \%$ confidence interval and $\mathrm{p}(0.5)$. The calculated $n(387)$ was from the total fresh undergraduate $(12,25)$ at Makerere during the time of study (2011-2012) (MUK, 2012).

\section{Procedure and data collection}

Intolerance of Uncertainty Scale (IUS) as described previously by Buhr \& Dugas (2002) was used in the study. The study employed the Generalized Anxiety Disorder Questionnaire for DSM IV (GAD-Q-IV) (Newman et al., 2002). The measure comprise of five dichotomous (yes or no) items-1, 2, 3, 4 and 6-measuring the presence of excessive and uncontrollable worry (for example, "Do you experience excessive worry?"), the $5^{\text {th }}$ item asks the respondent to list maximum of six most frequent topics of worry, the $7^{\text {th }}$ item is a checklist of six somatic symptoms related to GAD (for 
example, irritability, muscle tension), and the last two items ( $8^{\text {th }}$ and $\left.9^{\text {th }}\right)$ are questions assessing the degree of interference and distress experienced as a result of the worry and physical symptoms, scored on a 8-point Likert scale. A dimensional scoring system was applied, to compute the scores which provided a total index of the severity of GAD.

Parental attachment was measured with the Perceptions of Adult Attachment Questionnaire (PAAQ) (Cassidy et al., 2009). PAAQ, is a 60-item measure designed to assess two key aspects of attachment: (a) an individual's perceptions of his or her early childhood experiences with a primary caregiver (usually a mother), and (b) the individuals "current state of mind with respect to attachment". The self-report inventories were group administered in the class room to participants who consented to take part in the study, immediately after briefing on the research.

\section{Data analysis}

Data was analysed using Statistical Package for Social Science, version 16 (SPSS). In order to establish the prevalence of GAD among fresh undergraduates, the prevalence of GAD for the study population was computed, using the formula for computing prevalence, i.e., the total number of respondents who manifested GAD over the total number of sample surveyed, expressed in percentage. To examine the relationship between the dependent (GAD) and the independent variables (intolerance and parental attachment), Pearson's correlations were used. To test the association between the independent variables (intolerance of uncertainty and parental attachment) and the dependent variable (GAD), stepwise regression analysis was used.

\section{Ethical considerations}

The research received ethical approval from School of Psychology, Makerere University Ethical Review Committee. Participants' written informed consent was also obtained before completing the questionnaires. Participants for the study were adequately briefed in their class rooms- on the objectives, purpose, significance, duration of the research, and their rights and level of involvement.

\section{Results}

\section{Demographic characteristics of the participants}

A total of 401 respondents were sampled out of which fourteen (3.5\%) respondents did not take part in the study because of significant missing data (partial completion of questionnaires). The 387 respondents (males=231; females=156) who correctly completed the questionnaires were from the following colleges: Agriculture and Environmental Sciences; Business and Management Sciences; Computing and Information Sciences; Education and External Studies; Engineering, Design, Art and Technology; Natural Sciences; Humanities and Social Sciences and Veterinary Medicine, Animal Resources and Biodiversity, corresponding to $11.1 \%, 6.5 \%, 10.6 \%, 15.5 \%, 5.9 \%, 5.9 \%$, $11.4 \%, 28.7 \%$ and $10.3 \%$ respectively. The ages of the respondents ranged from 18 to 34 years (mean $=21.24$; standard deviation $=2.34$ ).

\section{GAD's relationship with intolerance of uncertainty and parental attachment}

Generalized Anxiety Disorder (GAD) symptoms were quite common. A total of $112(28.9 \%)$ of the respondents scored 5.7 (cut off point for GAD) and above on the GAD- Q- IV measure. Pearson's correlation coefficient, showed a significant positive relationship between GAD (GAD - Q -IV) and intolerance of uncertainty (IUS), $(r=0.30 ; p<0.01)$. Likewise, there was a significant positive relationship between GAD (GAD - Q - IV) and parental attachment (PAAQ60), $(r=0.21 ; p<0.01)$. Age also showed a significant negative relationship with GAD symptoms $(r=-0.11 ; p<0.05)$. However, sex did not show a significant relationship with GAD symptoms (mean $=3.8$ male, 4.2 female; $p=0.15$ ). The results are consistent with the hypothesis of a significant positive 
relationship between the independent variables (intolerance of uncertainty and parental attachment) and dependent variable (GAD).

In univariate regressions analyses, with age entered as a cofounder, IUS and parental attachment independently predicted GAD symptoms $(r=0.30,95 \%$ confidence interval $(\mathrm{Cl})=0.30$ to $6.16, p=0.001$ and $r=0.21,95 \%(C I)=0.21$ to $4.19, p=0.001$, respectively). In a multiple regression model where both independent variables and age were entered, IUS and parental attachment were still predictive of GAD symptoms, $(r=0.33,95 \%(\mathrm{Cl})=0.25$ to $4.85, \mathrm{p}=0.001$ and $r=0.33,95 \%(C l)=0.11$ to $2.16, p=0.031$, respectively). These results showed a positive relationship between GAD symptoms, and the independent variables, intolerance of uncertainty and parental attachment, and a negative relationship between GAD symptoms and age. A high intolerance of uncertainty score is correlated with high GAD symptoms, while a high score in parental attachment measure (insecure attachment) is correlated with high GAD symptoms. With regard to age, those in their late teens and early twenties manifested higher levels of GAD symptoms, than those in their late twenties and early thirties (mean $\pm S D=4.8(3.7) 16-19$ years versus $2.7(2.2) \geq 28$ years, $p=0.037)$.

\section{Discussion}

Results from the study provided support to accept the research hypotheses that there is a significant positive relationship between intolerance of uncertainty and GAD symptoms and also between parental attachment and GAD symptoms. The current study has for the first time, established the prevalence of GAD symptoms and provided evidence of the roles of intolerance of uncertainty and parental attachment in predicting GAD symptoms among fresh undergraduates in Uganda. Similarly, other studies elsewhere (Behar et al., 2005; Hale et al., 2006; Sugiura, 2007; Cassidy et al., 2009; Tan et al., 2010) have also supported the roles of cognitive and social factors in the development and maintenance of GAD. The prevalence of GAD symptoms among the participants was higher than the 3.0\% annual prevalence rate of GAD in the general population in low income countries (Lee et al. (2009).

Although the current study showed no difference between male and female manifestations, a previous study by Tyrer \& Baldwin (2006) showed that chronic worry is twice common in women than men, the current study showed no difference. This study demonstrated an inverse relationship between age and GAD symptoms with those in their late teens and early twenties manifesting higher levels of GAD symptoms. Similar findings that GAD symptoms are age dependent have been reported elsewhere (Hoge et al., 2004; Tyrer \& Baldwin, 2006; Allgulander, 2012).

In this study, the majority of the students did not meet criteria for GAD diagnosis (Newman et al., 2002). However, they manifested GAD symptoms to varying degree. Some of the students worried over diverse things including failure to do assignments, being late to class, failure to pay tuition fees, broken relationship, parents falling sick, likelihood of not getting a job after graduation, fear of sickness and death (data not shown). The intensity of the worry varied, from excessive to not excessive and from uncontrollable to controllable. Some of the students who did not meet the criteria for GAD manifested physical symptoms including restlessness, irritability, difficulty falling or staying asleep, difficulty concentrating or mind going blank, easily fatigued to muscle tension. Some of the apparently normal students were bothered to a varying degree by the worry and physical symptoms and in some there was interference with personal life, relationship with others and academic activities. These findings are consistent with the previous studies (Ruscio \& Borkovec, 2004; Sugiura, 2007; Tan et al., 2010).

The development and evolution of GAD symptoms among the students resulted from the activation of anxious and worrisome vulnerability in the face of challenging circumstances (Ozan et al., 2010). The anxious and worrisome vulnerability were determined by many factors, for example cognitive and social factors. The way a student sees, thinks and interprets situations, the 
quality of his interactions and relationship with his parents, are significant factors that shaped his vulnerability or resilience in the face of stressors (Bowlby, 1977; Behar et al., 2009).

Unlike in a study by Behar et al. (2009) which assessed five theoretical modes of GAD evolution, the present study considered two factors, intolerance of uncertainty and parental attachment. The current research has established the independent and collective nature of these factors in predicting GAD symptoms in Ugandan university students. Intolerance of uncertainty can paralyze a student, inhibit decision making, and trigger emotional distress and maladaptive behaviours. The student is afraid of change, uncertainty and ambiguity, leading in most cases to tension, worries, anxiousness, easy fatigability, disturbed concentration and attention (Dugas et al., 2004; Ruscio \& Borkovec, 2004; Behar et al., 2005; Holaway et al., 2006).

The current study provided support of a significant positive relationship between intolerance of uncertainty and GAD symptoms and also between parental attachment and GAD symptoms, findings comparable with the works of Tan et al. (2010). Other scholars have also provided support of the positive relationship between intolerance of uncertainty and GAD (Behar et al., 2005; Sugiura, 2007) and between parental attachment and GAD (Cassidy et al., 2006; Hale et al., 2006). Intolerance of uncertainty demonstrated a stronger significant positive relationship with GAD symptoms than parental attachment, consistent with results of a previous study in a non-clinical sample (Tan et al., 2010). Parental attachment underscores the role of parent-child interactions, in the development and maintenance of GAD. The home could be a secure place for a student while growing up into an adult or a source of tension and trauma. The attitude and behaviour of parents are crucial in making their homes a secure base for their children's growth, development and successful engagement with the world (Bowlby, 1977; Hale et al., 2006).

The independent variables, (intolerance of uncertainty and parental attachment) and age independently and jointly were significant predictors of the dependent variable, (GAD symptoms). Intolerance of uncertainty was a better predictor of GAD symptoms than parental attachment and age both independently and jointly, and this is consistent with the works of other scholars, that cognitive factors, for example intolerance of uncertainty are critical in the development and maintenance of GAD (Dugas et al., 2004; Behar et al., 2005; Sugiura, 2007; Tan et al., 2010). The present study does not imply causality; a longitudinal study will be needed to explore the possible theoretical models of GAD's aetiology and their strengths in predicting GAD symptoms (Behar et al., 2009).

Ozan et al. (2010) have shown that students commonly manifest GAD symptoms, and this is consistent with the results of the present study, though not without caution since the prevalence of GAD in the general population in Uganda is not known. However, it is plausible that a university with all its complexity may trigger anxious and worrisome vulnerability among fresh undergraduates, battling with new environment and the challenges of balancing personal, interpersonal, parental and academic expectations amidst tasking circumstances (Hale et al., 2006; Viana \& Rabian, 2008; Ozan et al., 2010).

The present research is not without limitations. It is limited in its cross-sectional nature; only fresh undergraduates were sampled, and from one university of the many universities in Uganda, which lowers the extent results generated, can be extrapolated to the general population. It also suffered from general apathy to research and lack of cooperation, many students refused to complete the questionnaires and simply walked away with them. A screening instrument was used to assess for GAD prevalence which may account for the high rate compared to rates by other scholars. Another limitation was missing data; a few of the participants had to be excluded from the study because of significant missing data.

In conclusion, the present study provides support that GAD symptoms are prevalent among fresh undergraduates and that a significant positive relationship exists between GAD symptoms and intolerance of uncertainty and parental attachment. The present study calls for an efficient and effective approach of screening, diagnosing and treating GAD symptoms, which it 
has established to be common among fresh undergraduates. Future studies will be needed to establish the prevalence of GAD among the entire undergraduate population in Uganda and explore other theoretical models in the evolution and maintenance of GAD symptoms. Future researches should also identify other cognitive and social predictors in the development and evolution of GAD in both students and the general population to inform appropriate interventions

\section{Acknowledgements}

We are immensely grateful to Prof. Peter Baguma, the Dean School of Psychology, Makerere University, Kampala and Dr. Janet Nambi, Head Department of Mental Health and Community Psychology for their contributions. We would like to thank Mr. Simon Kizito and Dr. Rosco Kasujja, for their tutelage and support.

\section{Authors' Contributions}

GCU conceptualized and designed the study and was responsible for data collection, analysis and manuscript writing. PB supervised the entire processes of study conceptualization and design, data collection and analysis and manuscript writing.

\section{Conflict of Interest}

None.

\section{References}

Allgulander, C. (2012) Generalized anxiety disorder: a review of recent findings. Journal of Experimental Clinical Medicine 4: 88-91.

Ansseau, M., Fischler, B., Dierick, M., Mignon, A. \& Leyman, S. (2005) Prevalence and impact of generalized anxiety disorder and major depression in primary care in Belgium and Luxemburg: the GADIS Study. Journal of European Psychiatry 20: 229-235.

Behar, E., Dimarco, I.D., Hekler, E.B., Mohlman, J. \& Staples, A.M. (2009) Current theoretical models of generalized anxiety disorder (GAD): Conceptual review and treatment implications. Journal of Anxiety Disorders 23: 1011-1023.

Behar, E., Zuellig, A.R. \& Borkovec, T.D. (2005) Thought and imaginal activity during worry and trauma recall. Behavior Therapy 36:157-158.

Bowlby, J. (1977) The making and breaking of affectional bonds. I: Aetiology and psychopathology in the light of attachment theory. British Journal of Psychiatry 130: 201210.

Buhr, K. \& Dugas, M.J. (2002). The intolerance of uncertainty scale: Psychometric properties of the English version. Behavior Research and Therapy 40: 931-946.

Cassidy, J., Lichtensein-Phelps, J., Sibrava, N.J., Thomas, C.L. \& Borkovec, T.D. (2009) Generalized anxiety disorder: connection with self-reported attachment. Behavior Therapy 40: 23-38.

Comer, J.S. \& Kendall, P.C. (2004). A symptom-level examination of parent-child agreement in the diagnosis of anxious youth. Journal of the American Academy of Child and Adolescent Psychiatry 43: 878-886.

Dugas, M.J., Schwartz, A. \& Francis, K. (2004) Intolerance of uncertainty, worry, and depression. Cognitive Therapy and Research 28: 835-842.

Hale, W.W., Engels, R. \& Meeus, W. (2006) Adolescent's perception of parenting behaviours and its relationship to adolescents' general anxiety disorder symptoms. Journal of Adolescence 29: 407-417. 
Hoge, E.A., Oppenheimer, B.A. \& Simon, N.M. (2004) Generalized anxiety disorder: review. Journal of Lifelong Learning in Psychiatry 2: 346-359.

Holaway, R.M., Heimberg, R.G. \& Coles, M.E. (2006) A comparison of intolerance of uncertainty in analogue obsessive-compulsive disorder and generalized anxiety disorder. Journal of Anxiety Disorders 20: 158-174.

Hudson, J.L. \& Rapee, R.M. (2002) Parent-child interactions in clinically anxious children and their siblings. Journal of Clinical Child and Adolescent Psychology 31: 548-555.

Israel, G.D. (2012) Determining sample size; PEOD6, Agricultural Education and Communication Department Florida Cooperative Extension Services, Institute of Food and Agriculture Services, University of Florida: Retrieved, July 10, 2012 from http://edis.ifas.ufl.edu.

Jinyao, Y., Xiongzbao, Z., Auerbach, R.P., Gardiner, C.K., Lin, C., Yuping, W. \& Shuqiao, Y. (2012) Insecure attachment as a predictor of depression and anxious symptomatology. Depression and Anxiety 29: 789-796.

Kessler, R.C., Chui, W.T., Demler, O., Merikangas, K.R. \& Walters, E.E. (2005) Prevalence, severity, and comorbidity of 12-month DSM-IV disorders in the National Comorbidity Survey Replication. Archives of General Psychiatry 62: 617-627.

Lee, S., Tsang, A., Ruscio, A.M., Haro, J.M., Stein, D.J., Alonso, J., Angermeryer, M.C., Bromet, E.J., Demyttenaere, K., de Girolamo, G., de Graaf, R., Gureje, O., Iwata, N., Karam, E.G., Lepine, J.P., Levinson, D., Medina-Mora, M.E., Oakley Brown, M.A., Posada-Villa, J. \& Kessler, R.C. (2009) Implications of modifying the duration requirement of generalized anxiety disorder in developed and developing countries. Psychological Medicine 39: 1163-1176.

MUK (2012) Makerere University Kampala. University official site: Retrieved, August 11, 2012, from http://ar.mak.ac.ug/ar/admlist_link.php?act

Munk-Jorgensen, P., Allgulander, C., Dahl, A.A., Foldeger, L., Holm, M., Rasmussen, I., Virta, A., Hunhtanen, M.T. \& Wittchen, H.U. (2006) Prevalence of generalized anxiety disorder in general practice in Denmark, Finland, Norway and Sweden. Psychiatric Services 57: 17381744.

Newman, M.G., Zuellig, A.R., Kachin, K.E., Constantino, M.J. \& Cashman-McGrath, L. (2002) Preliminary reliability and validity of the generalized anxiety disorder questionnaire IV: A revised self-report diagnostic measure of generalized anxiety disorder. Behavior Therapy 33: 215-233.

Ozan, N.S., Ercan, I., Irgil, E. \& Sirgirl, D. (2010) Anxiety prevalence and affecting factors among university students. Asia Pacific Journal of Public Health 22:127-134.

Ruscio, A.M. \& Borkovec, T.D. (2004) Experience and appraisal of worry among high worriers with and without generalized anxiety disorder. Behaviour Research and Therapy 42: 14691482.

Sugiura, Y. (2007) Responsibility to continue thinking and worrying: Evidence of incremental validity. Behaviour Research and Therapy 45: 1619-1628.

Tan, S., Mouding, R., Nedeljkovic, M. \& Kyrios, M. (2010) Metacognitive, cognitive and developmental predictors of generalized anxiety disorder symptoms. Clinical Psychologist 14: 84-89.

Tyrer, P. \& Baldwin, D. (2006) Generalized anxiety disorder. Lancet 368: 2156-2166.

Viana, A.G. \& Rabian, B. (2008) Perceived attachment: Relations to anxiety sensitivity, worry and GAD symptoms. Behaviour Research and Therapy 46: 737-747.

Wittchen, H.U., Kessler, R.C., Beesdo, K., Krause, P., Hofler, M. \& Hoyer, J. (2002) Generalized anxiety disorder and depression in primary care: prevalence, recognition, and management. Journal of Clinical Psychiatry 63 (Suppl.8): 24-34.

Wood, J.J. (2006) Parental intrusiveness and children's separation anxiety in a clinical sample. Child Psychiatry \& Human Development 37, 73-87. 